\title{
Activity of antimicrobial peptide fractions of human serum and saliva against clinically important yeasts
}

\author{
Vera Arzumanian ${ }^{1}$, Taisia Erofeeva ${ }^{1}$, Asiya Ixanova ${ }^{1}$, Polina Zhigalkina ${ }^{2, *}$ and Oxana Svitich ${ }^{3}$ \\ ${ }^{1}$ Laboratory of Fungal and Bacterial Physiology, Mechnikov Research Institute for Vaccines and Sera; \\ ${ }^{2}$ Federal State Autonomous Educational Institution of Higher Education, I. M. Sechenov First Moscow \\ State Medical University of the Ministry of Health of the Russian Federation (Sechenov University); \\ ${ }^{3}$ Laboratory of Molecular Immunology, Mechnikov Research Institute for Vaccines and Sera, \\ Moscow, Russia.
}

\begin{abstract}
Every human bioliquid contains substances possessing direct antimicrobial activity. These substances include complement system proteins of serum, immunoglobulins of serum and epithelial secretions, and antimicrobial peptides/proteins (AMP) with low molecular masses, which are present at all sites and liquids of human body. The aim of this study is to estimate the AMP fraction activity of serum and saliva towards different clinically important yeasts. Specimens of serum and saliva were obtained from 10 healthy volunteers - 5 women and 5 men, 20-26 years old. Strains of yeasts Candida albicans, Rhodotorula mucilaginosa, Malassezia furfur, Cryptococcus neoformans, Geotrichum candidum, Trichosporon cutaneum and Saccharomyces cerevisiae were used in the experiments. Native (total) liquids and their AMP fractions obtained by filtration through a membrane of $100 \mathrm{kDa}$ were used in the process of antimicrobial activity estimation carried out by the spectrophotometric method. The AMP activities were 2.3-13.5 fold lower than the corresponding total ones, the yeasts most susceptible to serum AMP were C. albicans and Cr. neoformans. Total salivary antifungal activities were 3.6-5.2 fold lower than the corresponding total serum activities. Total activity of saliva was significantly higher
\end{abstract}

\footnotetext{
*Corresponding author: polinkav_95@mail.ru
}

towards $R$. mucilaginosa, while that of the other ones were almost the same. AMP activities of saliva were 1.1-3.8 fold lower than the total ones. $R$. mucilaginosa and T. cutaneum were the most sensitive to AMP fraction of saliva. Gender difference with regard to the activity of the studied bioliquids was also observed: the most significant ratio was obtained for the sensitivity of C. albicans to women/men salivary AMP. Based on the above data one can conclude that among the studied yeast genera/species show specificity to AMP. It is expressed in terms of the varying sensitivity of the yeasts to the AMP fraction in serum and saliva.

KEYWORDS: serum, saliva, antimicrobial peptides, Candida albicans, Cryptococcus neoformans, clinical yeasts.

\section{INTRODUCTION}

Human bioliquids contain more than 20 antimicrobial peptides/polypeptides (AMP) with molecular mass 2.8-80 kDa [1, 2]. Cytoplasmic membrane of microorganisms is the main target of AMP which electrostatically interact to form channels in the membrane. Selective action of different AMP depends on the electrical charge of the membrane and its chemical formulation, that is to say the availability of sterols, glycosphingolipids etc. [3]. Therefore each AMP should have specificity 
toward certain microbe species. This specificity is expressed in the form of minimal inhibitory concentration (MIC) towards different microbes. Since in each bioliquid occurred several AMP so the integral AMP specificity should take place.

Recently we have estimated total antimicrobial activity of different human bioliquids in comparison with the activity of their AMP fractions as markers of local immunity. Based on the most appropriate estimation of antimicrobial activity of different human secretions [4] we determined that the most active among all human bioliquids was serum. The antimicrobial defense of the vaginal secretions was mainly due to the activity of its AMP fraction. In the case of urine AMP do not play a significant role [5]. Because serum and saliva were not diluted prior to analysis, these bioliquids could be accurately used in the study aimed to demonstrate the integral specificity of AMP towards different clinically important yeasts.

\section{MATERIALS AND METHODS}

Specimens were obtained from 10 healthy volunteers - 5 women and 5 men 20-26 years old. Specimens of blood and saliva were harvested in the morning prior to breakfast, while saliva was obtained after tooth brushing and oral rinsing by water. Sera were obtained by standard procedure: incubation of blood specimens for $1 \mathrm{~h}$ at $37^{\circ} \mathrm{C}$, and at $8{ }^{\circ} \mathrm{C}$ during night and centrifugation for $15 \mathrm{~min}$ at $7000 \mathrm{rpm}$. Every specimen was filtered through the membrane filter Millipore having a pore diameter of $0.22 \mu$, freezed at $-25^{\circ} \mathrm{C}$ and then thawed out before the experiment, centrifuged for $5 \mathrm{~min}$ at $16000 \mathrm{rpm}$ and the supernatant prior to the filtration was used for the further procedures (fraction "Total") or filtered through a membrane of $100 \mathrm{kDa}$ («Amicon ultra», Germany) (fraction “AMP”).

Yeasts strains used for all experiments - Candida albicans № 927, Rhodotorula mucilaginosa № 132, Malassezia furfur № 1451, Cryptococcus neoformans № 3465, Geotrichum candidum № 1206, and Trichosporon cutaneum № 18 were selected from the laboratory collection, but Saccharomyces cerevisiae Y-375 was selected from Russian Collection of Microorganisms (Puschino, Russia). Cultivation of yeast strains was carried out in Petri dishes with solid
Sabouraund medium supplemented with antibiotis at $25{ }^{\circ} \mathrm{C}$ for $19 \mathrm{~h}$, while $M$. furfur was grown on Dixon`s medium at $32{ }^{\circ} \mathrm{C}$ for $24 \mathrm{~h}$.

Estimation of antimicrobial activity was carried out by the following procedure: $50 \mu \mathrm{l}$ of yeast suspension (final concentration of cells about $10^{9}$ $\mathrm{CFU} / \mathrm{ml}$ ) was combined with $400 \mu \mathrm{l}$ of specimen in an Eppendorf tube. Control sample contained $400 \mu 1$ of normal saline solution instead of the analyzed specimen. The mixture was incubated on shaker at $32{ }^{\circ} \mathrm{C}$ for 2 hours, and after that centrifuged for $5 \mathrm{~min}$ at $16000 \mathrm{rpm}$; the supernatant was removed and $300 \mu$ of the dye $2 \mathrm{mM}$ bromocresol purple in $1.25 \mathrm{M}$ phosphate buffer ( $\mathrm{pH}$ 4.6) was added and incubated again for $45 \mathrm{~min}$. After centrifugation $50 \mu \mathrm{l}$ of the supernatant was dissolved in $2.5 \mathrm{ml}$ of the same buffer and the optical density was measured at a wavelength of $440 \mathrm{~nm}$ using a spectrophotometer ("Genesys 10S UV-Vis", USA). These procedures were carried out three times. The antimicrobial activity was calculated as the percent of dye accumulated in the destroyed cells compared to the control [6].

Statistical evaluation of obtained results was carried out by parametric and nonparametric methods of 'MS Excel', and 'Statistica for Windows'.

\section{RESULTS}

Using the adequate spectrophotometric method the total and AMP activities of serum and saliva were estimated (Table 1). From the data we can draw the conclusion that total antimicrobial activities of sera towards different yeast species were not similar: they were significantly low against basidiomycetes Cryptococcus neoformans, Rhodotorula mucilaginosa, Malassezia furfur and Trichosporon cutaneum compared to ascomycetes yeasts Candida albicans, Geotrichum candidum and Saccharomyces cerevisiae. At the same time AMP activities were 2.3-13.5 fold lower than the corresponding total ones, and the yeasts most susceptible to serum AMP were C. albicans and $\mathrm{Cr}$. neoformans. It is important to note that variances in AMP activity values were more significant compared to the total activity.

Total salivary antifungal activities were 3.6-5.2 fold lower than the corresponding total serum activities. Total activity of saliva was significantly 


\begin{tabular}{|c|c|c|c|c|c|c|c|}
\hline \multirow{4}{*}{ 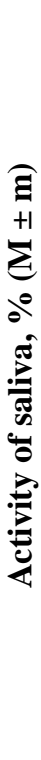 } & $\begin{array}{l}{ }^{*} \\
\overbrace{}^{*} \\
\overbrace{}^{\tilde{w}}\end{array}$ & & 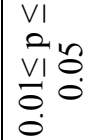 & $\begin{array}{l}\hat{n} \\
0 \\
\hat{0} \\
\hat{2}\end{array}$ & $\begin{array}{l}\hat{n} \\
0 \\
0 \\
\hat{2} \\
2\end{array}$ & $\begin{array}{l}n \\
0 \\
0 \\
\hat{n} \\
2\end{array}$ & $\begin{array}{l}\tilde{0} \\
0 \\
0 \\
\hat{2} \\
2\end{array}$ \\
\hline & 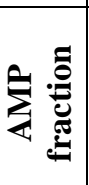 & $\begin{array}{l}0 \\
\infty \\
+1 \\
H \\
\end{array}$ & $\begin{array}{l}0 \\
\infty \\
+1 \\
\ddot{0} \\
\ddot{n}\end{array}$ & $\begin{array}{l}\stackrel{m}{+} \\
+ \\
+ \\
\vec{n}\end{array}$ & $\begin{array}{l}\infty \\
\dot{n} \\
+1 \\
\ddot{0} \\
-\end{array}$ & $\begin{array}{l}\stackrel{0}{r} \\
+ \\
\ddot{+}\end{array}$ & 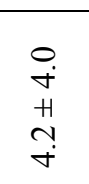 \\
\hline & " & & $\begin{array}{l}\text { vI } \\
20 \\
\text { vil } \\
0 \\
0 \\
0 \\
0\end{array}$ & $\begin{array}{l}n \\
0 \\
0 \\
\hat{n} \\
\tilde{a}\end{array}$ & $\begin{array}{l}0 \\
0 \\
0 \\
\hat{n} \\
\hat{2}\end{array}$ & $\begin{array}{l}n \\
0 \\
0 \\
\hat{n} \\
\tilde{a}\end{array}$ & $\begin{array}{l}n \\
0 \\
0 \\
\hat{\alpha} \\
2\end{array}$ \\
\hline & 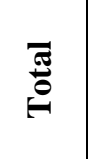 & 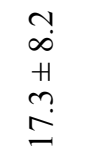 & $\begin{array}{l}\stackrel{a}{a} \\
+ \\
\vec{i} \\
\vec{d}\end{array}$ & $\begin{array}{l}n \\
n \\
1 \\
0 \\
a\end{array}$ & $\begin{array}{l}r \\
i \\
+1 \\
n \\
0\end{array}$ & $\begin{array}{l}\exists \\
0 \\
+1 \\
0 \\
\ddot{n}\end{array}$ & $\begin{array}{l}a \\
\ddot{n} \\
+1 \\
+ \\
\dot{0}\end{array}$ \\
\hline \multirow{4}{*}{ 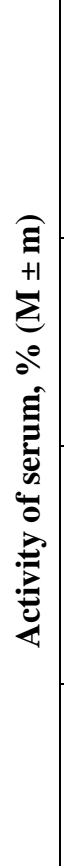 } & " & ' & $\begin{array}{l}n \\
0 \\
0 \\
\text { VI } \\
2 \\
\text { VI } \\
0 \\
0 \\
0\end{array}$ & $\begin{array}{l}\hat{0} \\
\dot{0} \\
\hat{a} \\
\hat{n}\end{array}$ & $\begin{array}{l}\overrightarrow{0} \\
\dot{0} \\
\text { VI } \\
2\end{array}$ & $\begin{array}{l}\overrightarrow{0} \\
\dot{0} \\
\mathrm{VI} \\
2\end{array}$ & $\begin{array}{l}n \\
0 \\
0 \\
\text { VI } \\
\stackrel{2}{1} \\
\text { vi } \\
0 \\
0\end{array}$ \\
\hline & 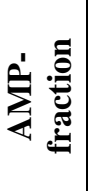 & $\begin{array}{l}\hat{\sigma} \\
+ \\
0 \\
\infty \\
\infty\end{array}$ & $\begin{array}{l}\overrightarrow{0} \\
\infty \\
+ \\
+ \\
\dot{0}\end{array}$ & 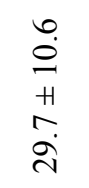 & $\begin{array}{l}\overrightarrow{0} \\
\dot{0} \\
+ \\
\dot{0} \\
\dot{0}\end{array}$ & $\begin{array}{l}\stackrel{+}{i} \\
\stackrel{H}{H} \\
\stackrel{n}{\sigma}\end{array}$ & $\begin{array}{l}\infty \\
\infty \\
+1 \\
\vec{n} \\
\ddot{\lambda}\end{array}$ \\
\hline & " & & $\begin{array}{l}\overrightarrow{0} \\
\dot{0} \\
\mathrm{~V} 1 \\
2\end{array}$ & $\begin{array}{l}\text { VI } \\
2 n \\
\text { VI } \\
\text { on } \\
0 \\
0\end{array}$ & $\begin{array}{l}\text { VI } \\
e_{n} n \\
\text { VI } \\
0 \\
0 \\
0\end{array}$ & $\begin{array}{l}n \\
0 \\
0 \\
\hat{a} \\
a\end{array}$ & $\begin{array}{l}\hat{n} \\
0 \\
0 \\
\hat{n} \\
2\end{array}$ \\
\hline & 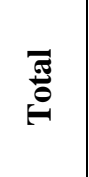 & $\frac{a}{+1}$ & 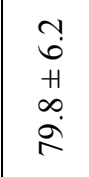 & $\begin{array}{l}\infty \\
\dot{0} \\
H \\
\tilde{1} \\
\tilde{\infty}\end{array}$ & $\begin{array}{l}0 \\
i \\
+1 \\
0 \\
\dot{\infty}\end{array}$ & $\begin{array}{l}\text { ̧े } \\
+ \\
+ \\
\dot{+}\end{array}$ & $\begin{array}{l}\stackrel{9}{+} \\
+ \\
a \\
\infty \\
\infty\end{array}$ \\
\hline & 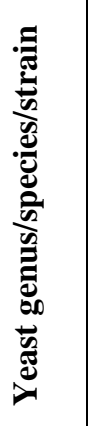 & 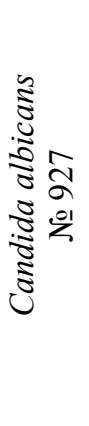 & 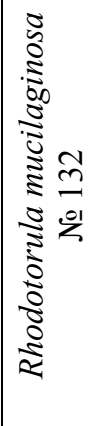 & 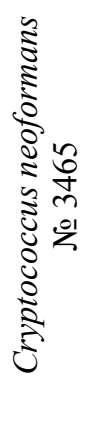 & 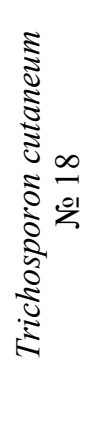 & 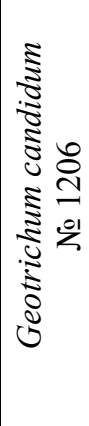 & 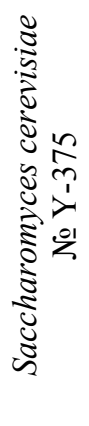 \\
\hline
\end{tabular}


higher towards R. mucilaginosa, while that of the other ones were almost the same. AMP activities of saliva were 1.1-3.8 fold lower than the total ones. The yeasts most sensitive to AMP fraction of saliva turned out to be $R$. mucilaginosa and $T$. cutaneum. However no correlation was observed between AMP activities of serum and saliva towards different yeasts species (Pirson's coefficient $r=-0.158$ ).
Differences in the AMP activities of serum as well as saliva were seen between the two gender groups (Figure 1A, B). Significantly higher serum AMP activity towards T. cutaneum was demonstrated in women compared to men ( $\mathrm{p} \leq$ 0.01 ), whereas other yeasts showed no significant variations in their susceptibility $(p>0.05)$. Salivary AMP activities demonstrated higher level only towards $C$. albicans and G. candidum in

A

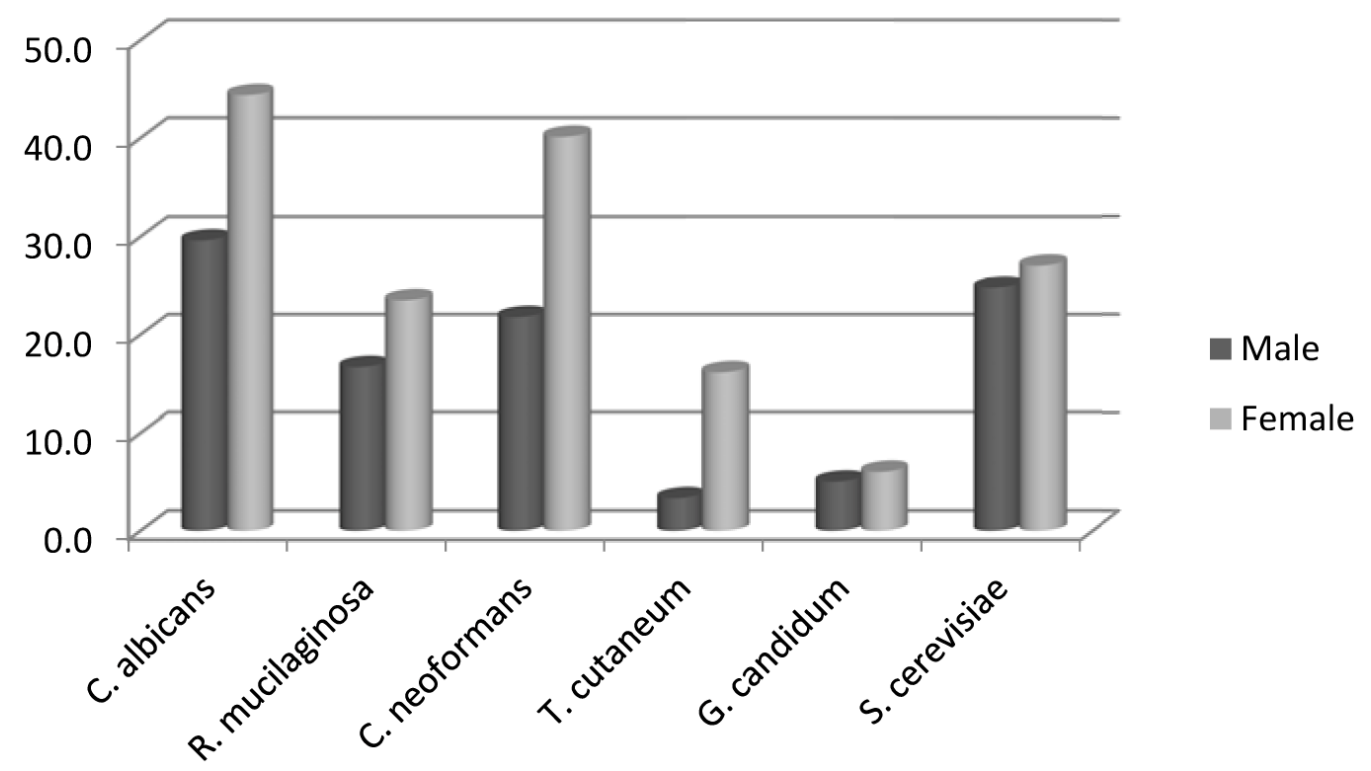

B

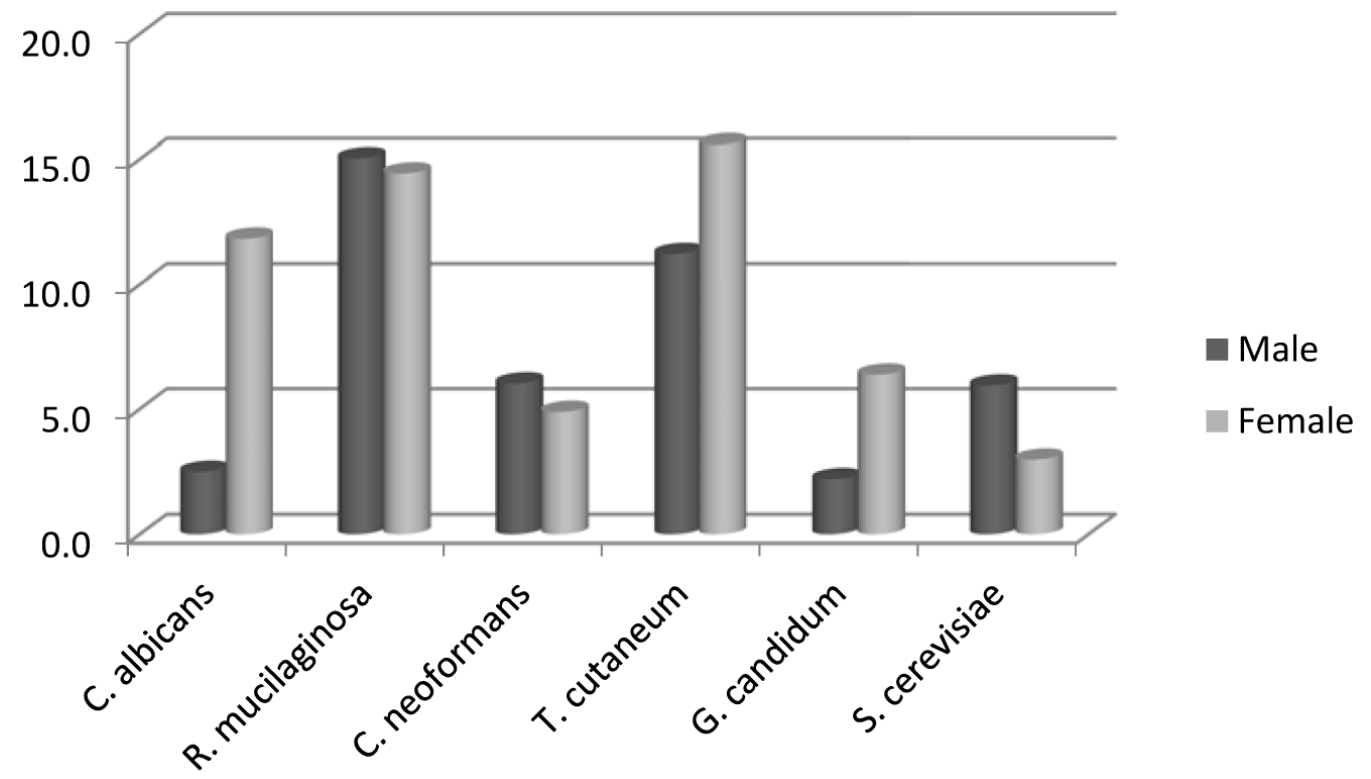

Figure 1. Activities of serum (A) and salivary (B) AMP fractions of males and females (medians). 
women compared to men $(0.01 \leq \mathrm{p} \leq 0.05)$, although the other yeasts showed no substantial differences in their sensitivity to the liquid.

\section{DISCUSSION}

Lower activities of total serum compared to total activities of total saliva could be attributed to the presence of complement system proteins in the serum. Moreover, it is evident that the AMP fraction activity in serum is much lower than in saliva (Table 1).

Antimicrobial activity patterns of (poly)pepetides in human serum and saliva in comparison with their minimal inhibiting concentrations (MIC) against $C$. albicans is demonstrated in Table 2 .
Obviously the AMP activity patterns in serum and in saliva are almost similar, except in case of dermcidins. From the table it is clear that the prevailing AMP in serum are dermcidins, lysozyme, RNAs and calprotectin. Two of these AMP (RNAs and calprotectin) occur in saliva in the same concentrations, but concentrations of histatins, defensins, SILP and psoriasin in the bioliquid are several times more than in serum. Moreover, known MIC values of the AMP against $C$. albicans are more often closer to their concentrations in saliva than in serum. Based on the data the salivary AMP fraction should be expected to be more active than the serum one, but comparison of the activities (Table 1) demonstrated the inverse result. One can assume that some of the AMP

Table 2. Antimicrobial activity patterns of (poly)pepetides in human serum and saliva in comparison with their minimal inhibiting concenrations (MIC) against C. Albicans.

\begin{tabular}{|c|c|c|c|c|c|c|}
\hline \multirow[t]{2}{*}{ Number } & \multirow[t]{2}{*}{ AMP } & \multirow{2}{*}{$\begin{array}{l}\text { Mol. } \\
\text { mass of } \\
\text { AMP, } \\
\text { kDa }\end{array}$} & \multicolumn{2}{|c|}{$\begin{array}{c}\log (\text { maximal AMP } \\
\text { concentration in bioliquid, } \\
\mathrm{ng} / \mathrm{ml})\end{array}$} & \multirow{2}{*}{$\begin{array}{l}\text { Log (MIC of the } \\
\text { AMP against } \\
\text { C. albicans, } \\
\text { ng/ml)* }\end{array}$} & \multirow{2}{*}{ *References } \\
\hline & & & In serum & In saliva & & \\
\hline 1 & Hepcidin & 2.8 & -1 & 1 & $5-6$ & [7] \\
\hline 2 & Histatins & $3.0-4.9$ & $\begin{array}{c}\text { No } \\
\text { quantitative } \\
\text { data }\end{array}$ & 5 & $4-5$ & {$[8]$} \\
\hline 3 & Defensins & $3.5-4.5$ & 1 & 5 & $4-5$ & {$[9,10]$} \\
\hline 4 & Cathelicidins & $4.5-19$ & 3 & 2 & $4-5$ & {$[11,12]$} \\
\hline 5 & Dermcidins & $5.1-9.4$ & 4 & Absent & $3-4$ & {$[13]$} \\
\hline 6 & Adrenomedullin & 6.0 & 1 & -2 & Absent & [14] \\
\hline 7 & Psoriasin & 11.4 & 3 & 5 & No data & - \\
\hline 8 & SILP & 11.7 & 2 & 5 & $5-6$ & {$[15]$} \\
\hline 9 & Lysozyme & 14.5 & 4 & 4 & $4-5$ & {$[16,17]$} \\
\hline 10 & RNAs & 14.5 & 4 & $\begin{array}{c}\text { No } \\
\text { quantitative } \\
\text { data }\end{array}$ & 3 & {$[18]$} \\
\hline 11 & Lipocalins & 25.0 & 3 & 3 & No data & - \\
\hline 12 & Azurocidine & 27.0 & 1 & -2 & No data & - \\
\hline 13 & Calprotectin & 36.5 & 4 & 4 & $4-5$ & [19] \\
\hline 14 & BPI & 55 & 2 & 2 & No data & - \\
\hline 15 & Lactoferrin & $76-80$ & 3 & 4 & 5 & {$[20]$} \\
\hline
\end{tabular}

*Significant differences between the activity against given yeast species and the activity against $C$. albicans. 
existed in more active form in serum than in saliva, or some new serum AMP would be created later.

Another intriguing fact was detected in the study: a specificity of AMP fractions of serum and saliva towards different yeasts species. It is known that different AMP selectively act on the microbe cytoplasmic membranes depending on their electrical charge or chemical composition (lipid) [3]. Electrical charge of bacterial membranes is usually negative, whereas eukaryotic cells of yeasts are electrically neutral. However we have no data about any differences among yeast genera. As for lipid structure of yeast membrane it is known that each species of Candida genus has distinctive sphingolipid molecular species [21]. Therefore if yeasts have differences within one genus they should have different lipid composition between genera. In other words the yeast species studied here will likely have different molecular targets for AMP. This speculation is confirmed by the obtained data: evidently, between the studied yeast genera/ species there is specificity to AMP. It is expressed in terms of the varying sensitivity of the yeasts to the AMP fraction in serum and saliva. Interestingly no correlation was observed between the two indexes which may be explained by the following: probably the different AMP took part in defense against the same yeasts species in serum and saliva. Gender difference in the activity of the studied bioliquids was observed: the most significant ratio was in the sensitivity of $C$. albicans to women/men salivary AMP (Figure 1B). This fact could be confirmed by the recent data concerning the frequency of the yeast in oral cavity [22]. Authors detected statistically significant relationship between the intensity of yeast growth and the gender $(P=0.01)$. However in every age group, the number of infected individuals was greater among females than males, and moreover abundant growth of yeast occurred most frequently in the youngest group of females. All this as a whole suggests that frequent contact with certain microbial agent results in the increase of not only the specific antibodies (immunoglobulins), but specific AMP. Recently we have demonstrated that immunization of mice with yeast antigens lead to elevation of both specific immunoglobulin and AMP fraction activity [6]. However, the mechanism of their action is not known yet.

\section{CONCLUSION}

The present study demonstrated the most significant differences among the AMP fraction activities of human serum towards different yeast species, with $C$. albicans being the most sensitive one to AMP. Gender difference with regard to the activity of both studied bioliquids was also observed, especially against C. albicans. Based on the above data one can conclude that among the studied yeast genera/species show specificity to AMP. It is expressed in terms of the varying sensitivity of the yeasts to the AMP fraction in serum and saliva.

\section{CONFLICT OF INTEREST STATEMENT}

The authors of this publication have research support from Mechnikov Research Institute for Vaccines and Sera (Moscow, Russia) and also conduct research in areas of interest similar to the business interests of Mechnikov Research Institute for Vaccines and Sera. We have no conflicts of interest to disclose.

\section{REFERENCES}

1. Levy, O. 2000, Blood, 96, 2664.

2. Dale, B. A. and Fredericks, L. P. 2005, Curr. Issues Mol. Biol., 7, 119.

3. Guimarães, L. L., Marcos, S., Toledo, M. S., Ferreira, F. A. S., Straus, A. H. and Takahashi, H. K. 2014, Front. Cell. Infect. Microbiol., 4, 138.

4. Arzumanian, V., Malbakhova, E., Foshina, E., Artemeva, T., Butovchenko, L., Vartanova, N. and Shmeleva, O. 2015, Patent RF № 2015113069/15.

5. Arzumanian, V. and Erofeeva, T. 2018, Uspekhi meditsinskoi mycologii, 18, 6 .

6. Arzumanian, V., Shmeleva, O. and Michailova, N. 2017, Med. Mycol. Open Access, 3, 23.

7. Tavanti, A., Maisettam, G., Del Gaudio, G., Petruzzelli, R., Sanguinetti, M., Batoni, G. and Senesi, S. 2011, Peptides, 32, 2484.

8. Han, J., Jyoti, M., Song, H-Y. and Jang, W. 2016, PLoS One, 11, 196. 
9. Cullor, J., Mannis, M., Murphy, C., Smith, L., Selsted, E. and Reid, W. 1990, Archives of Ophthalmology, 8, 861.

10. Feng, Z., Jiang, B., Chandra, J., Ghannoum, M., Nelson, S. and Weinberg, A. 2005, J. Dent. Res., 84, 445.

11. Frohm Nilsson, M., Sandstedt, B., Sørensen, O., Weber, G., Borregaard, N. and StåhleBäckdah, M. 1999, Infect. Immun., 67, 2561.

12. den Hertog, A., van Marle, J., van Veen, H., van't Hof, W., Bolscher, J., Veerman, E. and Amerongen, A. 2005, Biochem. J., 388(Pt. 2), 689.

13. Schittek, B., Hipfel, R., Sauer, B., Bauer, J., Kalbacher, H., Stevanovic, S., Schirle, M., Schroeder, K., Blin, N., Meier, F., Rassner, G. and Garbe, C. 2001, Nat. Immunol., 2, 1133.

14. Allaker, R. and Kapas, S. 2003, Regulatory Peptides, 112, 147.
15. Tomee, J., Hiemstra, P., Heinzel-Wieland, R. and Kauffman, H. 1997, J. Infect. Dis., 176, 740 .

16. Samaranayake, Y., Samaranayake, L., Wu, P. and So, M. 1997, APMIS, 105, 875.

17. Samaranayake, Y., Samaranayake, L., Pow, E., Beena, V. and Yeung, K. 2001, J. Clin. Microbiol., 39, 3296.

18. Harder, J. and Schroeder, J. 2002, J. Biol. Chem., 277, 46779.

19. Brandtzaeg, P., Gabrielsen, T., Dale, I., Müller, F., Steinbakk, M. and Fagerhol, M. 1995, Adv. Experim. Med. \& Biol., 371A, 201.

20. Bellamy, W., Wakabayashi, H., Takase, M., Kawase, K., Shimamura, S. and Tomita, M. 1993, Med. Microbiol. Immunol., 182, 97.

21. Singh, A., Prasad, T., Kapoor, K., Mandal, A., Roth, M., Welti, R. and Prasad, R. 2010 , OMICS, 14, 665.

22. Loster, J., Wieczorek, A. and Loster, B. 2016, Clin. Interv. Aging, 11, 1707. 